\title{
Edison's Views on Life and Death
}

\author{
An Interview with the Famous Inventor Regarding His Attempt to Communicate with the Next World
}

As Reported by Austin C. Lescarboura

CISON-the man who tric light, the phonograph, the motion picture, the nickel-iron storage battery the perfected dynamo and a vast collection of other devices entering into ou everyday life-is about to devote himself to something which is infinitely more interesting than teresting than any invention can ever be. Here we are, five hundred million huma beings, facing death sooner or later yet totally ignoran of what is to become of our personalities. And the sam can be said about our coming into this world, for life and

death remain the greatest mysteries of the ages. Several weeks ago the word was passed around to the effect that the great inventor was working on a device, or apparatus as he prefers to term it, to communicate with personalities which have passed on to another existence or sphere. Immediately the press of the United States and Europe announced that Thomas A. Edison had joined the ranks of the spiritists, which now number many a prominent scientist, author, inventor, physicist, engineer, clergyman, and so on. Soon the highly imaginative French writers drew pen pictures of Mr. Edison's apparatus serving as a telephone station or telegraph office or whatnot, where phorsons wishing to communicate with those who have persons wishing to communicate with those who have

A impression has been permitted to gain ground both impression has been permitted to gain ground both
here and abroad. "In the first place, I cannot conceive here and abroad. "In the first place, I cannot conceive
such a thing as a spirit," said Mr. Edison to the writer. He meant it, too. "Imagine something which has no weight, no material form, no mass; in a word, imagine nothing! I cannot be a party to the belief that spirits exist and can be seen under certain circumstances and can be made to tilt tables and rap and do other things of a similar unimportant nature. The whole thing is so absurd."

In fact, it was mainly for the reason of correcting the impression about Mr. Edison's activities in this latest field of research that the inventor granted the writer an interview. The apparatus which he is reported to be building is still in the experimental stage Obviously, Mr. Edison is too cautious and too well founded in the uncertainties of any new experimental work to say anything definite at the present time. However, he wishes to say the following, which is very significant in the light of his past record in so many fields of endeavor:

"I have been thinking for some time of a machine or apparatus which could be operated by personalities which have passed on to another existence or sphere. Now follow me carefully: I don't claim that our personalities pass on to another existence or sphere. I don't istence or sphere. I don't claim anything because I the subject. For that matter, no human being knows. But I do claim that it is possible to construct an apparatus which will be so delicate that if there are personalities in another expersonalities in another ex-
istence or sphere who wish istence or sphere who wish
to get in touch with us in this existence or sphere

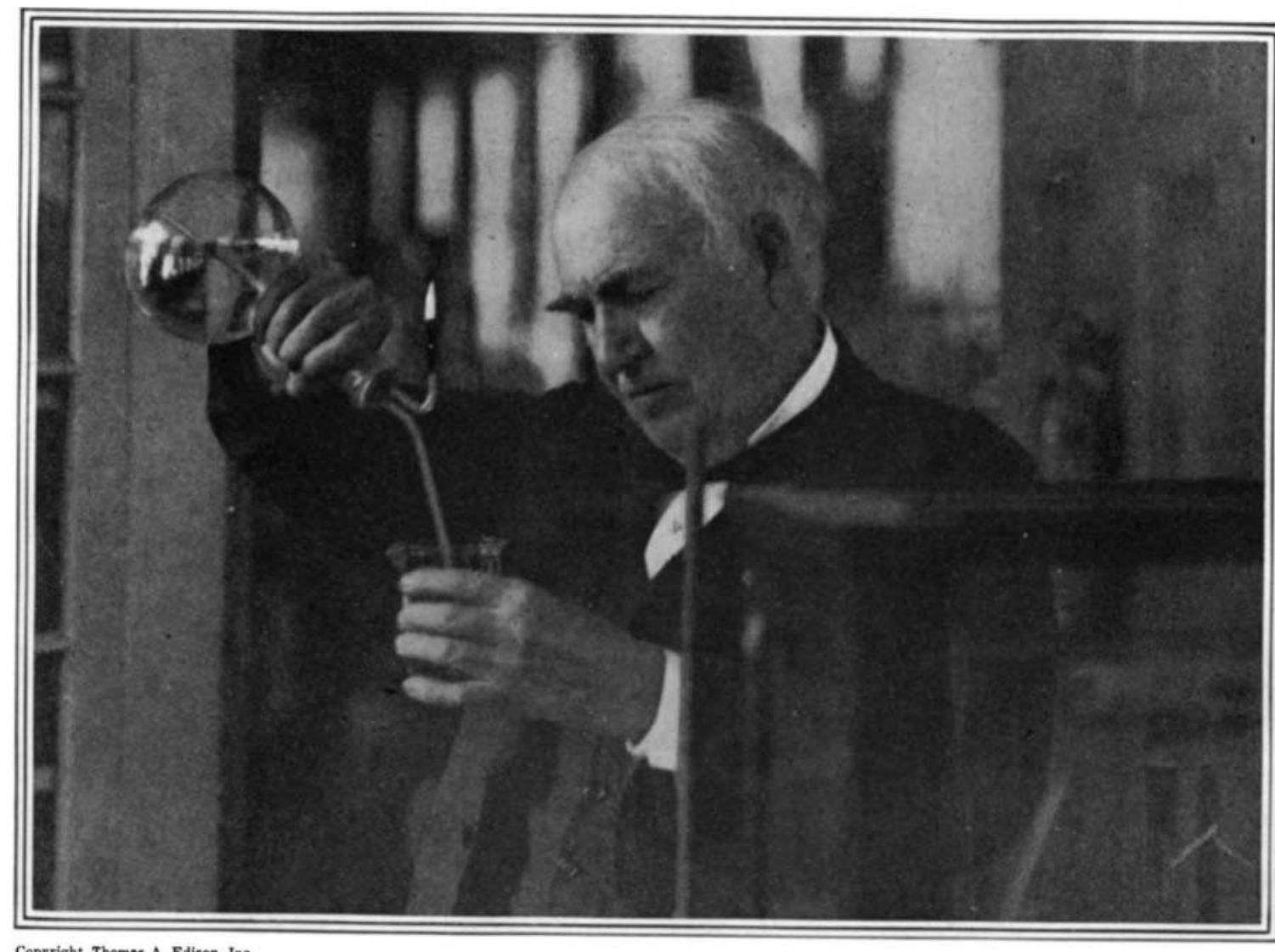

Thomas A. Edison-the world's foremost inventor-who is now at work on an apparatus designed to place psychical research on a scientific basis this apparatus will at least give them a better opportunity to express themselves than the tilting tables and raps and ouija boards and mediums and the other crude methods now purported to be the only means of communication.

"In truth, it is the crudeness of the present methods that makes me doubt the authenticity of purported com munications with deceased persons. Why should personalities in another existence or sphere waste their time working a little triangular piece of wood over board with certain lettering on it? Why should such personalities play pranks with a table? The whole business seems so childish to me that I frankly cannot give it $\mathrm{my}$ serious consideration. I believe that if we are to make any real progress in psychic investigation, we must do it with scientific apparatus and in a scientific manner, just as we do in medicine, electricity, chemistry, and other fields.

"Now what I purpose to do is to furnish psychic in vestigators with an apparatus which will give a scientific aspect to their work. This apparatus, let me explain, is in the nature of a valve, so to speak. That is to say, the slightest conceivable effort is made to exert many times its initial power for indicative purposes. It is similar to a modern power house, where man, with his relatively puny one-eighth horse-power, turns a valve which starts a 50,000-horse-power steam turbine. My apparatus is along those lines, in that the sliphtest tion with those who have passed out of this life. I merely state that I am giving the psychic investigators an apparatus which may help them in their work, just as optical experts have given the microscope to the medical world. And if this apparatus fails to reveal anything of exceptional interest, I am afraid that I shall have lost all faith in the survival of personality s we know it in this existence."

Mr. Edison does not believe in the present theories of life and death. Long ago he turned his back on the various old and accepted theories because he felt that they were fundamentally wrong. And just as he experimented with one substance after another without ever becoming discouraged in his search for the filament of the first successful incandescent electric lamp, so he has searched and reasoned and built up a structure which represents his theories of what is life.

"I believe that life, like matter, is indestructible," began Mr. Edison, in outlining his theory of life and death. "There has always been a certain amount of life on this world and there will always be the same amount. You cannot create life; you cannot destroy life; you cannot multiply life.

I believe our bodies are composed of myriads and myriads of infinitesimal entities, each in itself a unit of life, which hand together to build a man. We have taken it for granted that each of us is a unit. We , a horse, a fish and so on as units. 1 am convinced ally wrong. All these things appear to be units only for the reason that the life entities of which I speak are far too small to be detected even with the ultra-microscope.

"The question has been raised that if these life entities are so small, they cannot be large enough to include a collection of organs capable of carrying on the tasks which I am about to mention. Yet why not? There is no limit to the smallness of things, just as there is no limit as to largeness. The electron theory gives us a reply which is wholly satisfactory. I have had the matter roughly calculated and have at hand the data of the calculation. I am sure that a highly organized entity, consisting of millions of electrons yet still remaining too small to be visible through any existing microscope, is possible.

"There are many indications that we human being act as a community or ensemble rather than as units. That is why I believe that each of us comprises mil(Continued on page 458) 
Why Your Car Has A Breather Tube

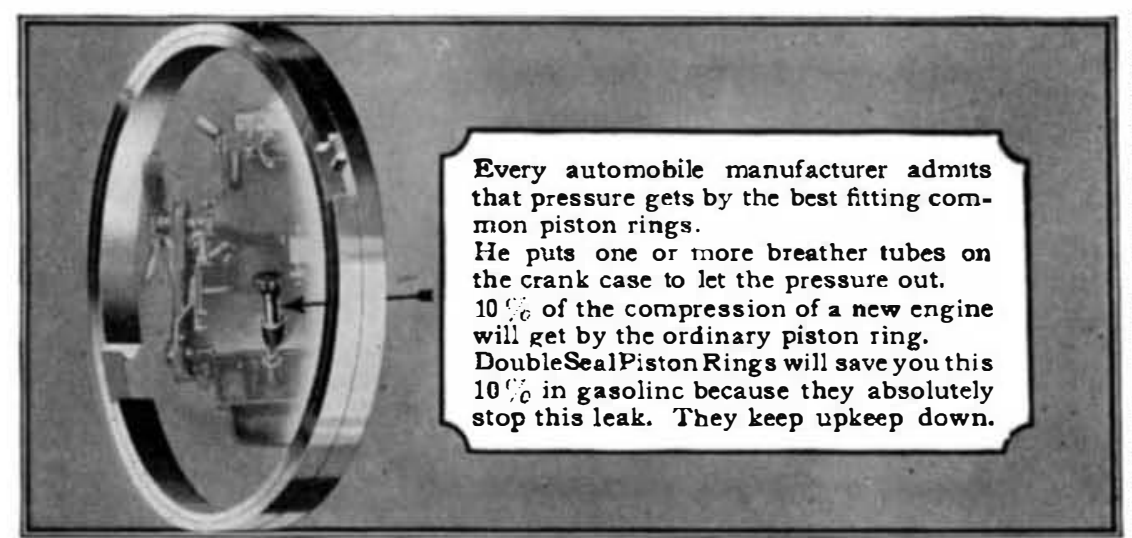

DOUBLE SEAL RING CO.

General Sales Office, 2335 Michigan Avenue, CHICAGO

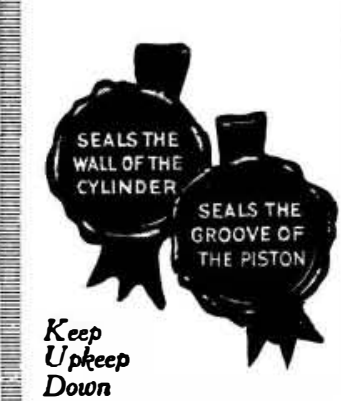

If your jobber, dealer or garage does not carry Double Seal Rings, address our nearest sales branch. Each branch carries in stock all sizes of rings.

Sales Branches of the Double Seal Ring Company

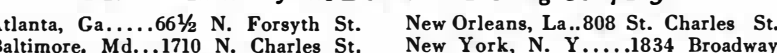
New York, N. Y .....1834 Broad
Oklahoma City, Okla $\ldots . . .416$ N.

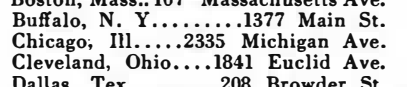
Dallas, Tex........208 Browder St
Denver, Colo.....430 Eighteenth St.
Detroit, Mich...924 Grand River Detroit, Mich.....924 Grand River El Paso, Tex........412 Myrtle Ave.
Fresno, CCal.....1922 Tuolumne St.
Ft. Worth, Tex...316.328 Lake St. Kansas City, Mo.....214 E. 17th St.
Little Rock, Ark ...414 Louisiana St.
Los Angeles, Cal....603 w. Pico St. Los Angeles, Cal....603 W. Pico St.
Memphis, Tenn....128 Monroe Ave. Memphis, Ten n...825

$S E A$

$D O U B L E$

$S E A L$

\section{$P I S T O N R I N G S$}
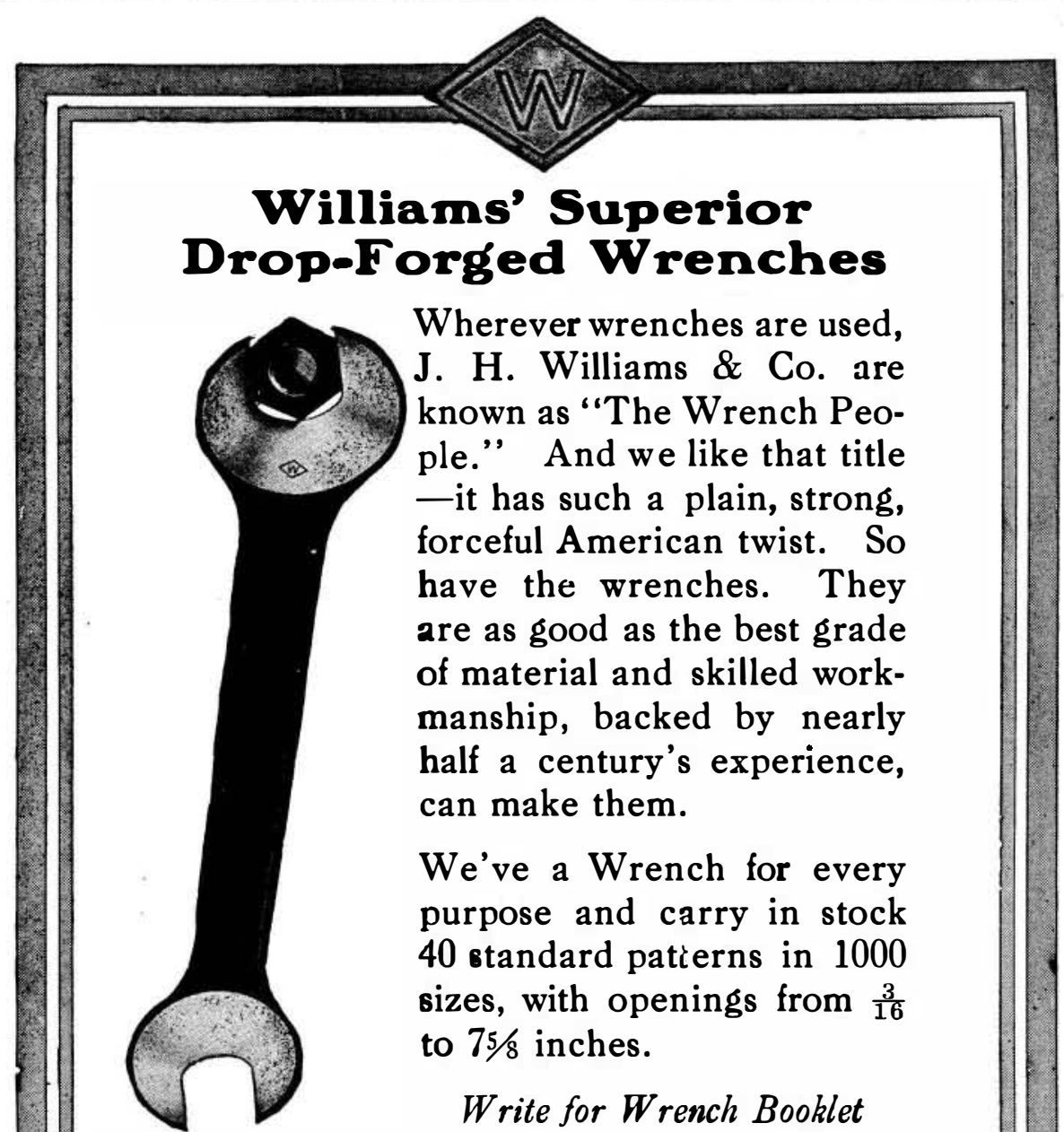

Wherever wrenches are used, J. H. Williams \& Co. are known as "The Wrench People." And we like that title -it has such a plain, strong, forceful American twist. So have the wrenches. They are as good as the best grade of material and skilled workmanship, backed by nearly half a century's experience, can make them.

We've a Wrench for every purpose and carry in stock 40 standard patierns in 1000 sizes, with openings from $\frac{3}{16}$ to $75 / 8$ inches.

Write for Wrench Booklet

\section{J. H. WILLIAMS \& CO. "The Wrench People"}

ly suited; for it makes it feasible to equip every car with its own drive. The multiple-unit train, where every car or every other car is self-impelled, exerts a much augmented tractive effort, so that it can reach full speed in a brief while after a stop. Where high-voltage, direct current is used, on the other hand, the locomotive is relied upon generally to do all of the pulling, and only its driving wheels are tractors. Accordingly, it takes longer to acquire or to resume maximum headway, and the condition of the tracks may interfere with this to such an extent as to impose the hauling of fewer cars.

On mountain sections, where high-voltage alternating-current distribution is provided, and the locomotives are driven by induction motors, the problem of handling heavy freight trains is radically dling heavy freight trains is radically form pace and good speed which these form pace and good speed which these
tractors can maintain both up and down tractors can maintain both up and down
grade. Further, this type of tractor grade. Further, this type of tractor places a minil

In densely settled areas, railway electrification has occasioned two reflex vexations. Alternating-current systems give rise to a phenomenon known as inductive interference, which is apt to upset the operation of nearby telegraph and teleoperation of nearby telegraph and tele-
phone lines. This annoyance has been phone lines. This annoyance has been pretty effectually reduced by the proper bonding of the rails so that the return circuit is taken care of in a way to obviate the disturbance of neighboring systems of communication. Inductive interference, like a mischievous boy, promptly betrays its activities in an audible manner. Direct current, however, promotes the electrolysis of underground conduits, etc. and the extent of its silent, insidious and destructive work is very frequently not detectable until collapse of the pipes, structure, etc., takes place. Then the

age may be of a very costly nature.

It is probable that no one system will be accepted to the exclusion of all others, but when a system is selected for a given railroad the decision should be made only after careful consideration not alone of the problems of that particular line but also of those of its neighbors-in this way achieving as complete a measure of

\section{California's Seaweed Industry} (Continued from page 445)

The process of manufacture is ingenious and interesting in view of the fact that they designed all the machinery and equipment for a purpose entirely new. The whole takes seventy-two hours but operation necessarily is continuous. The leaves and stems of the algæ are used. One of the most clever conceptions in the factory is a battery of four "mortars" or bowls twenty-two inches in diameter and fourteen deep in a solid block of concrete with corresponding quadruple wooden with corresponding quadruple wooden chanical scale of the primitive method chanical scale of the primitive method
of grinding. Into these mortars the raw of grinding. Into these mortars the raw
material or dry weed is first placed and in a few minutes it is stamped into a fine mass. The object is to free it of the millions of tiny shells, bits of sand, alkaline deposits and other foreign matter. Then it goes through various tanks and vats, one containing a secret solution for bleaching and the others plain water for washing, after which it is run through for washing, after which it is run through a wringer and spread on racks to dry in
the California sun. It looks like white the Cali

Next it is boiled three to four hours, filtered, distributed in galvanized iron trays four feet long, two wide and three inches deep, and five hours later it comes out jelled, like a large sheet of rubber. In this form it comes to the sharp knives of another wonderful machine, which cuts it into pieces a foot long and two lengthwise as are noodles. Having now undergone extreme heat a siege of the undergone extreme heat a siege of the
opposite character is provided, for it is placed on wooden trays and carried into reom and for ten ours kept at ten degrees below zero. The sticks come out solid ice. They are slowly melted, the water drained off, then put through a forcing machine which flatens each "noodle" into a thin, transparent sheet. Again the California sun is nvoked to dry them. Finally they are tied in three-pound sheaves of silvery sheen, and thus they first go into the market.

The factory is also making a superio vegetable isinglass as an experiment and the owner believes he can approach in quality, at low cost, the Russian mineral singlass now selling for $\$ 11.50$ a pound. An adhesive plaster, photographic films and other products are included in his plans, which thus far have in nowise been disappointing. Potash, iodine and other by-products of the algæ will be conserved, appliances for that purpose being in course of installation.

Edison's Views on Life and Death Continued from page 446)

lions upon millions of entities, and that our body and our mind represent the vote or the voice, whichever you wish to call it, of our entities.

"Now let's see why we must be composed of life entities. Supposing you take finger print of your thumb, in the conentional manner of the police records. Then burn your thumb sufficiently to detroy the skin. Do you know that after the new skin has formed the finger print of your recovered thumb will be precisely the same as the first one? Yes, absolutely the same, even down to the last line and irregularity. I tried it to make sure. Here is a mystery which has remained unanswered until now.

"Of course, you say it is nature. But what is nature? That seems to me to be such an evasive reply. It means nothing. It is just a subterfuge-a convenient way of shutting off further questioning by merely giving an empty word for an anthat word 'nature.' Now my answer is that the skin didn't happen to grow that way again by accident. Someone had to plan the new growth and to supervise it to make certain that it would conform in every way with the old skin. You do not know just what that pattern is, and so your brain plays no p:tt in the operation.

"Here is where our life entities come nto action. I firmly believe that the life entities rebuild that thumb with consummate care, drawing upon their remarkamemory for all the details.

"Let us consider an analogy, for the sake of making my point more clear to you. Supposing that a man from Mars came to this earth, and his eyes were so much coarser than ours that the smallost thing he could see was the Brooklyn Bridge. He could not see us. Naturally, he might take Brooklyn Bridge for some natural growth, just as we consider grass, sand, minerals and other things as mat ters of natural development. Supposing that same man from Mars were to destroy he Brooklyn Bridge, and several years later he happened to find a new bridge in precisely the same place and of preisely the same design. Would it seem ogical for that man to assume that the bridge simply grew again in the same manner and in the same place? Don't you suppose that the Martian would be compelled to assume that some intelligence and guided effort were behind the rebuilding of the structure he had detroyed?

"That is precisely the stand we should ake regarding the life entities. Obvious$y$, the entire matter is one of conjecture. 'erhaps the entities in our bodies are ninety-five per cent workers and five per cent directors. At any rate, it is the enemble of all these entities which gives us our physical form, ment

"The entities are life, I again repeat. 


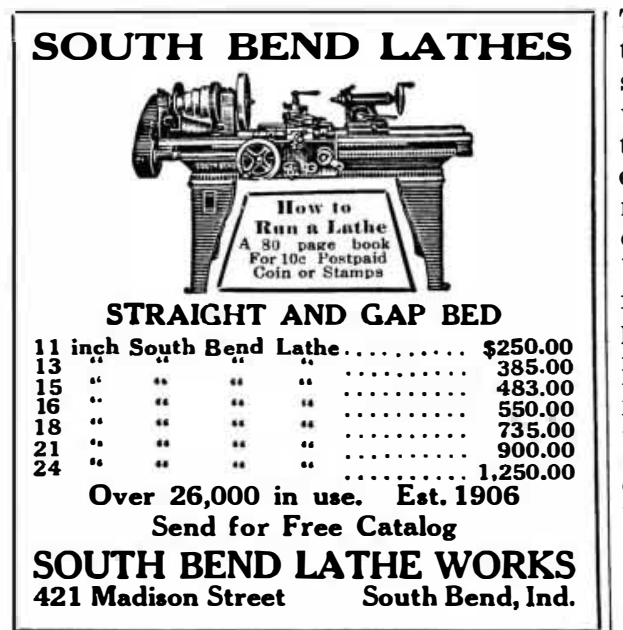

We WiIl Malie It
Anyything in a metal stamping or novelty pro-
duced from any metal and finished in any color.
Waterbury Button Co., Waterbury, Conn.

For Gunsmiths, Tool Makers, Experimental \& Repair Work, etc.

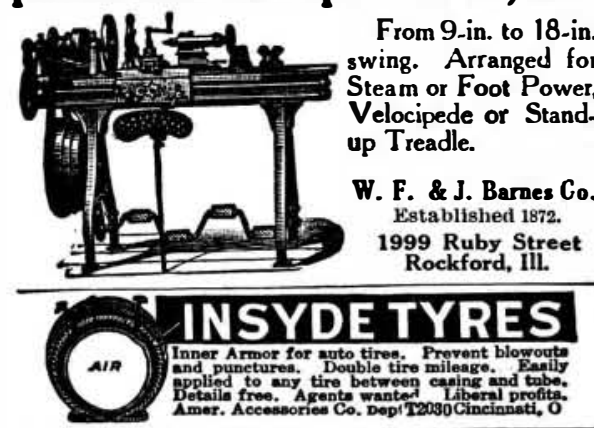

UNISOL BOILER PRESERVER

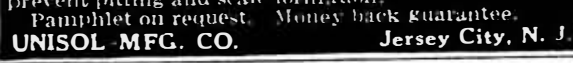

1R MACHINES Corliss Engines, Brewers UL The VILTER MFG. CO.
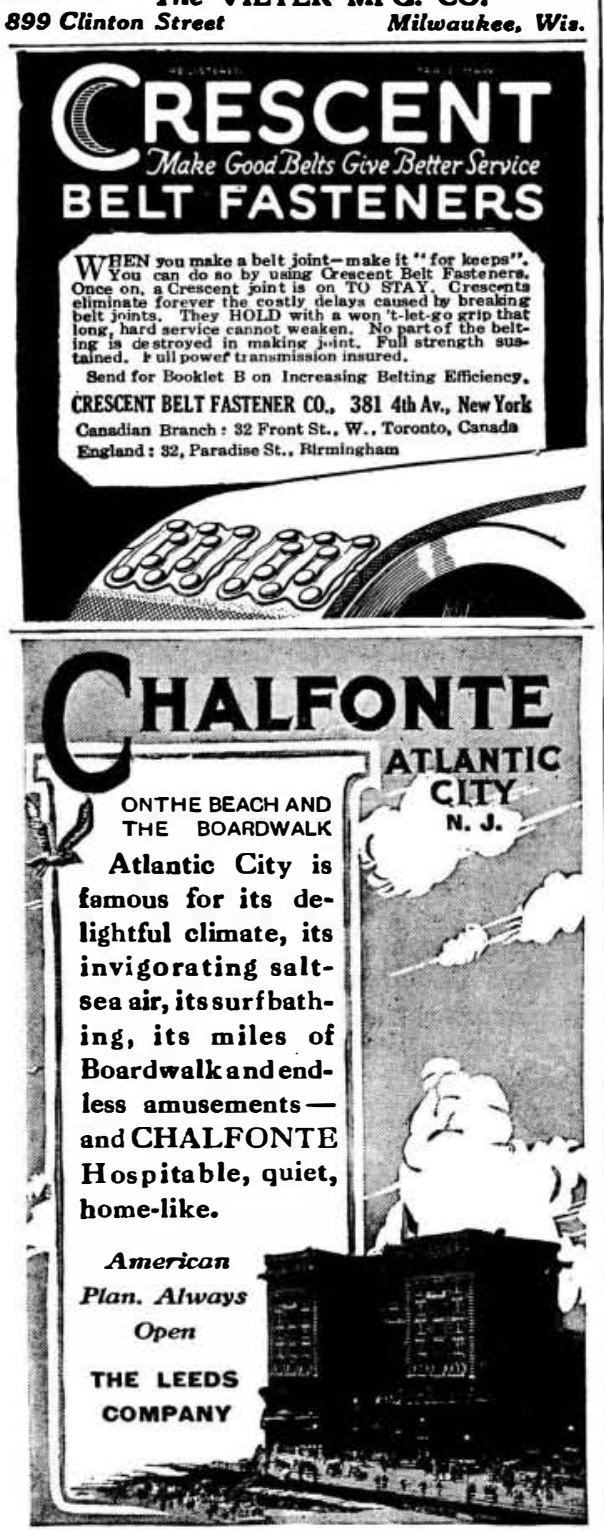

They are steady workers. In our bodies these entities constantly rebuild our tissues to replace those which are constantly vearing out. They watch after the functions of the various organs, just as the engineers in a power house see that the machinery is kept in perfect order. Once conditions become unsatisfactory in the body, either through a fatal sickness, fatal accident or old age, the entities simply depart from the body and leave little more than an empty structure behind. Being indefatigable workers, they naturally seek something else to do. They either enter into the body of another man, or even start work on some other form of life. At any rate, there is a fixed number of these entities, and it is the same entities that have served over and over again for everything in this universe of ours, although the various combinations of entities have given us an erroneous impression of new life and still new life for each generation.

"The entities live forever. You cannot destroy them, just the same as you cannot destroy matter. You can change the form of matter; but of gold, iron, sulfur, oxygen and so on, there w'as the same quantity in existence in the beginning of this world as there is today. We are simply working the same supply over and over again. True, we change the combinations of these elements, but we have not chan of these elements, but we have not changed the relative quantities of each of the elements with which we started. So with the life entities, we cannot destroy them. They are being used over and over again, in different forms, to be sure, but they are always the same entities.

"The entities are so diversified in their capabilities that it is difficult to identify their handiwork in all instances. Thus today the scientists admit the difficulty of drawing a line of demarcation indicating where life ends and inanimate things begin. It may be that life entities even extend their work to minerals and chemicals. For what is it that causes certain solutions to form crystals of a very definite and intricate pattern? Nature! But what is nature? Is it not fair to even suspect that life entities may be at work suspect that life entities may be at work
building those crystals? They don't simbuilding those crystals? They don't simply happen. Something must cause certain solutions alway

kinds of crystals. ality. The reason why you are Lescarboura and I am Edison is because we have different swarms or groups or whatever you wish to call them, of entities. After eighty-two remarkable surgical operations the medical world has conclusively proved that the seat of our personality is in that part of the brain known as the fold of Broca. Now it is reasonable to suppose that the directing entities are located in that part of our bodies. These entities, as a closely-knit ensemble, give us our mental impressions and our personality.

"I have already said that what we call death is simply the departure of the entities from our body. The whole question to my way of thinking, is what happens to the master entities-those located in the fold of Broca. It is fair to assume that the other entities, those which have been doing purely routine work in our body, disband and go off in various directions, seeking new work to do. But how about seeking new work to do. But how about those which have been directing things in our body-those which are Lescarboura, Edison, Meadowcroft and so on? Do they remain together as an ensemble or do they also break up and go about the universe seeking new tasks as individuals and not as a collective body? If they break up and set out as individual entities, then I very much fear that our personality does not survive. While the life entities live not survive. While the life entities live forever, thus giving us the eternal life which many of us hope for, this means little to you and me if, when we come to that -stage known as death, our personality simply breaks up into separate units which soon combine with others to form new structures.

"I do hope that our personality survives.
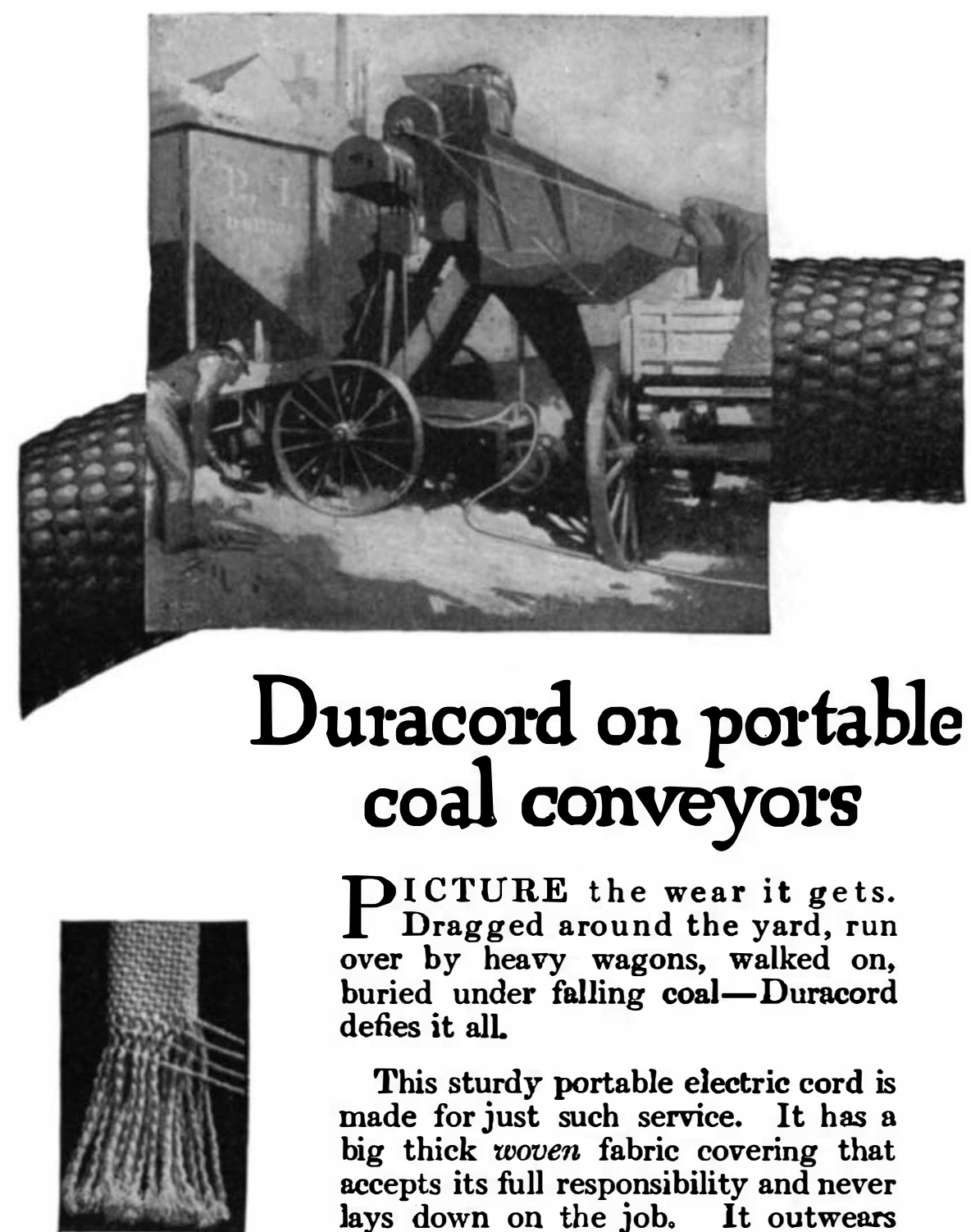

DICTURE the wear it gets. Dragged around the yard, run over by heavy wagons, walked on, buried under falling coal-Duracord defies it all.

This sturdy portable electric cord is made for just such service. It has a big thick woven fabric covering that accepts its full responsibility and never lays down on the job. It outwears ordinary cord many times.
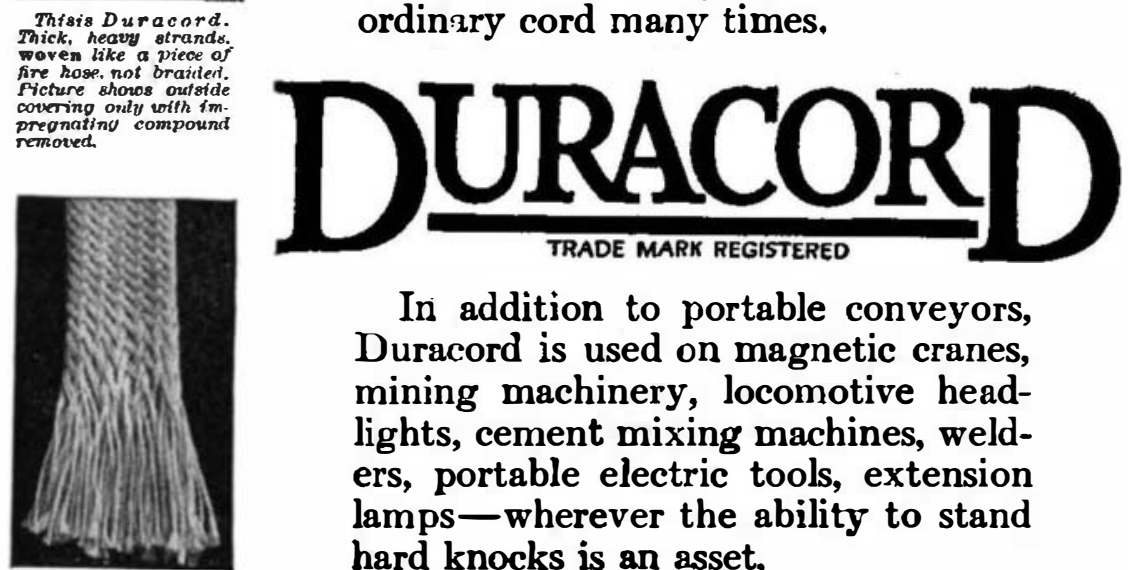

In addition to portable conveyors, Duracord is used on magnetic cranes, mining machinery, locomotive headlights, cement mixing machines, welders, portable electric tools, extension lamps - wherever the ability to stand hard knocks is an asset.

Duracord is made in all sizes of portable electric cord and the larger sizes of single and duplex cable. Ask your electrical jobber or let us send you samples of Duracord and ordinary cord for you to test and compare yourself.

TUBULAR WOVEN FABRIC CO. Pawtucket, R. I.

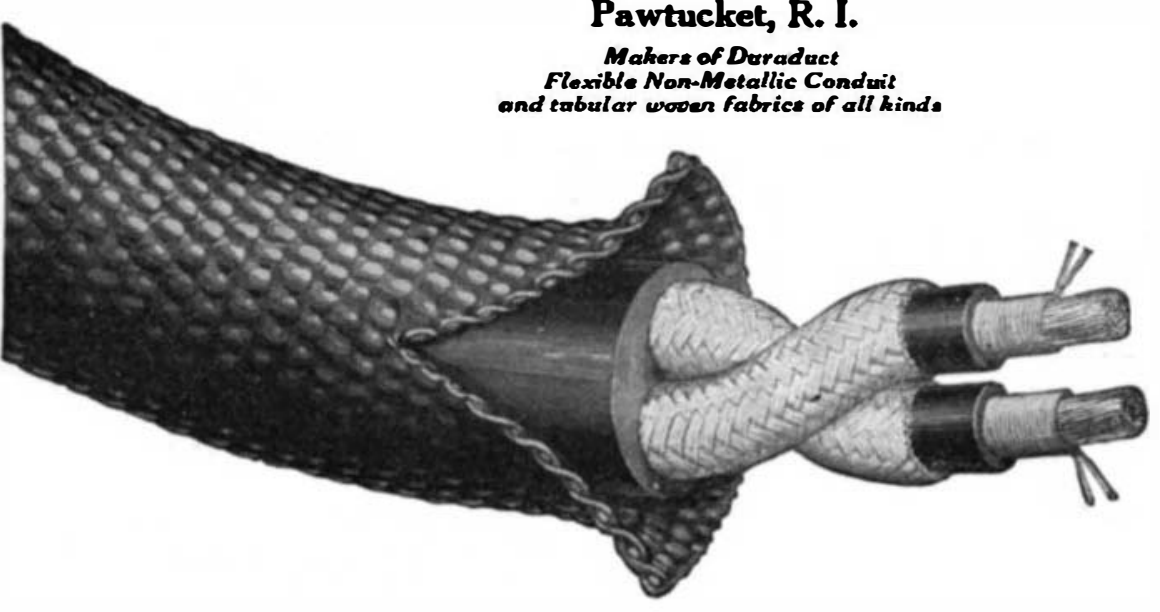


W. L. Douglas \$7.00 \$8.00 \$9.00 \& \$10.00 SHOES FOR MEN AND WOMEN

YOU GAN SAVE MONEY BY WEARING W. L. DOUglas shOES

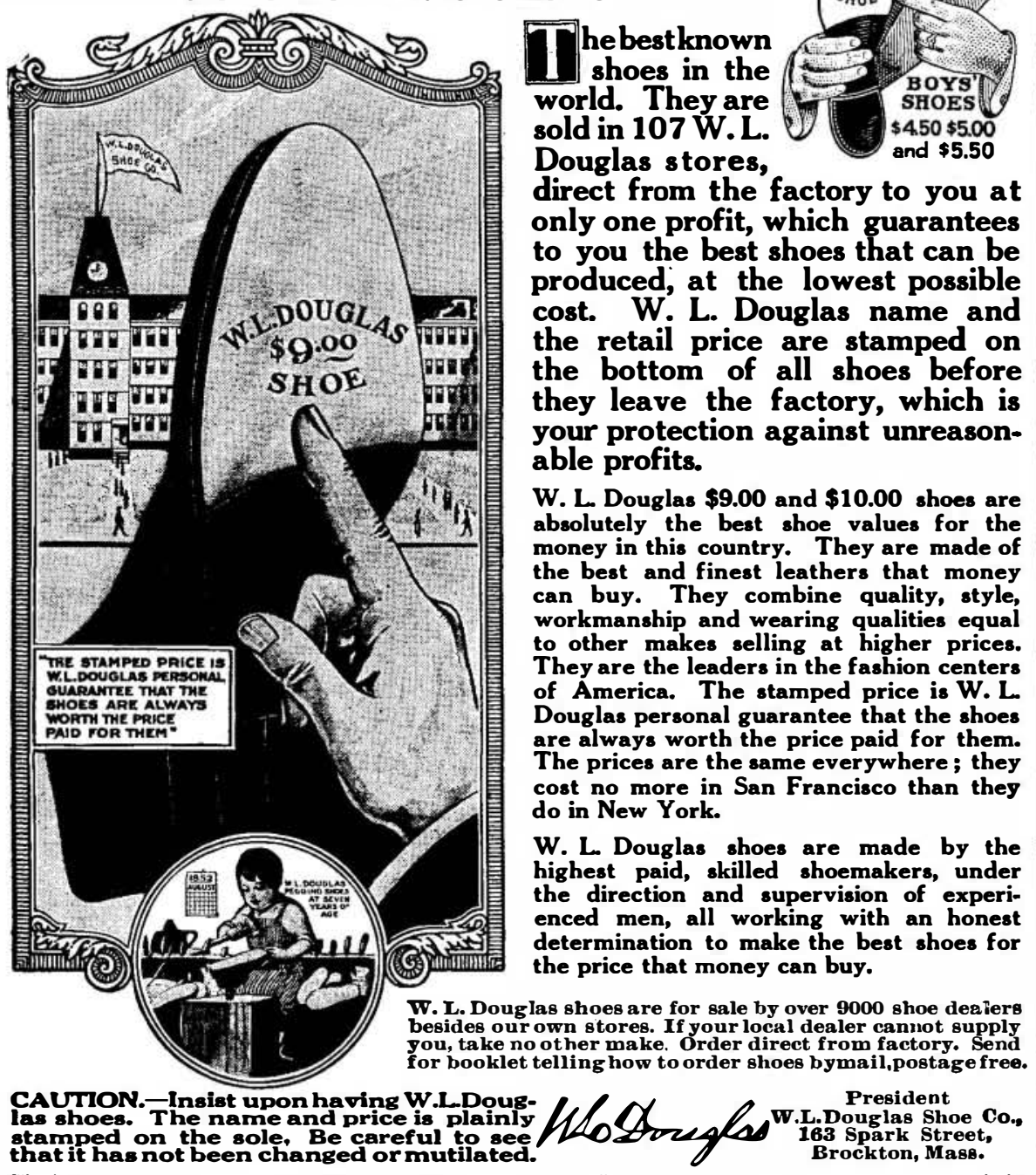

|

\section{R E L AT I V I T Y}

\section{The Special and the General Theory}

By Professor Albert Einstein, Ph.D. LL.D.

Translated by Professor Robert W. Lawson, M.Sc.

$T$

HE authorized English translation of Einstein's own book explaining his theories to the general public is now available. Dr. Einstein has scored a conspicuous success in this volume, steering a skillful course between the twin dangers of too much mathematics and too little explanation. Also, he makes clearer than has yet been made just wherein lies the dividing line between his special theory and his general theory, and just where the two join. In literary style as well as in clarity of exposition this book bids fair to take rank as a classic; and in any event, it is by far the most satisfactory treatment of the subject to be had at the presen date in English.

\section{Price $\$ 2.50$, by Mail $\$ 2.58$}

For Sale by

SCIENTIFIC AMERICAN PUBLISHING CO. 233 Broadway
If it does, then my apparatus ought to be of some use. That is why I am now at have ever undertaken to build, and await the results with the keenest in terest.'

Getting a Line on Concrete Pipe (Continued from page 449)

type of the finished product can be compared with other joints of pipe made of specially prepared mixtures, the comparison reflecting the character of materials, proportions, water content and other in gredients.

Permeability tests are conducted upon the completion of the tensile-strength investigation, the same specimens being used. A concrete block, one side of which conforms to the inside surface of the specimen, constitutes the testing apparatus. It is held against the surface by two clamps. Water is furnished through a one-fourth-inch iron pipe running through the tester to the surface to be
tested. Escape of water is barred by an tested. Escape of water is barred by an inflated gasket seated in a groove around the edge of the tester. Fifty pounds of water pressure is applied for one-half hour. The quantity of sweat or seepage is noted at 5-minute intervals. Specimens are air-cured 29 hours and watercured 3 weeks. Absorption tests are made on the same specimens. These are dried on the same specimens. These are dried
out in an electric oven to constant weight out in an electric oven to constant weight
and then immersed in water. Weights are and then immersed in water. Weights are taken at one-half hour, 4 hours and 48 hours. The percentage of absorption is based on dry weight

Definite results, although not comprehensive because of the incompleteness of the investigation, are available from the experiments. An outstanding conclusion is that proper grading of select material is the most essential factor in the manu facture of an excellent quality of concret pipe. The porosity of a pipe is influenced largely by the grading of the material. Rock dust up to 10 per cent and clay free from organic matter up to 5 per cent have proven their efficacy in preventing seepage without decreasing th strength of the pipe.

Lahoratory tests show that a substantially large variation in water content does not materially influence the strength of the pipe, conditional upon the mixture being heavily tamped. Under light tamping, pipe made of a so-termed "dry mixture" is much weaker and seeps freely. A first-rate quality of broken rock of uniform toughness insures the strongest pipe. This may be attributable to the difficulty of finding gravel free from soft or disintegrated particles in California. The breaking strength of concrete pipe under water pressures varies widely, the variation being due to the manner of testing. If a pipe is thoroughly saturated several days before the test is made a good quality of pipe will test as high as when dry, while a poor quality shows a decrease

That concrete expands and contracts when influenced by changes in temperature, is knowledge of general acceptance. i However, the information that a concrete pipe expands when changed from a dry to a wet condition and contracts to a like extent when the conditions are reversed crete pipe, when subjected to water pressure for some time, if permitted to dry, may contract as much as it would under may contract as much as it would under renheit. Excessive internal stresses in renheit. Excessive internal stresses in
concrete pipe, not infrequently resulting in ruptures, are created by having th ower part of a pipe line wet if not saturated and the upper part dry. Seepage through the shell of a pipe under water pressure will appear under low pressures nearly as rapidly as under high pressures. If water is going to percolate through a pipe, a pressure of 5 pounds to the square inch will indicate with reliable accuracy inch will indicate with reliable accuracy the quantity of
through the shell.
Hardening Steel in Gas-Fired Furnaces

(Continued from page 450)

of quenching is not quite so rapid, or as severe as water or brine, yet quick enough to give the proper hardness to most all

It is important to keep all quenching baths cool, and replenished from time to time with a fresh supply of the liquid. Where water is used it is best to keep up a fresh supply continuously. Oil baths are cooled either by a series of cold water pipes around the tank, an agitation of the oil by compressed air, or a circulation of the oil. The last-named method is perhaps the best as it not only causes a cooling o fthe oil but also a constant changing of the bath and takes the heated oil away from the metal after it gives up ts heat to the oil.

Quenching should be done rapidly but uniformly. Tongs for holding the work should have as small grip as possible. Long pieces of steel, including drills and reamers should be quenched with their axis vertical. Where this is impossible such as in very long round rods, they should be made to roll into the quenching bath with their long axis horizontal, but they should enter the bath very quickly. Round cutting tools should be immersed with their axis horizontal. Small tools or pieces should be kept in motion when placed in the cooling bath.

Warping occurs frequently in hardening steel pieces and may be attributed to one of two causes-uneven heating or quenching too long. Some pieces should be left in only long enough to harden extreme edges. Again it is often necessary to immerse the piece at an angle in order to overcome this difficulty. Therefore, it will be necessary to give considerable thought to the shape and design of the tool, in order to obtain the best results.

The Heavens in November, 1920 (Continued from page 452)

Jupiter is a morning star, rising at 1 A. M. in the middle of the month. Saturn is about seven degrees farther east, and rises half an hour later. The two. plants are on the borders of Leo and Virgo, and afford a fine spectacle in the morning sky. Uranus is in Aquarius, observable in the evening, and Neptune is almost opposite in the sky, and visible before day-

The moon is in her last quarter at 3 A. M. on the 3rd, new at 11 A. M. on the 10th, in her first quarter at $3 \mathrm{P}$. M. on the $18 \mathrm{th}$, and full at $9 \mathrm{P}$. M. on the 25 th. She is nearest the earth on the 27th, and farthest off on the 15th. During the month she passes near Neptune on the 3 rd, Jupiter on the 5 th, Saturn on the 6th, Mercury on the 11th, Venus on the 13 th, Mars on the 15th, Uranus on the 18th, and Neptune again on the 30th. On the morning of the 10th there occurs a partial eclipse of the sun, which is ern portions of the United States, and as far west as Kansas. The eclipse begins about 9 A. M. eastern time and lasts more than two hours for observers in New England and the Middle States, about onethird of the sun's diameter being obscured on the northern side. The magnitude of the eclipse will be smaller, and the dura. tion shorter for observers farther south and west, till it fades away to nothing in Alabama and Arkansas.

\section{Do Moths Use "Wireless"?}

$\mathrm{T}^{\mathrm{T}}$ has for long been known that cer-

tain species of moths are able to communicate with one another even though separated by a considerable distance. This fact is to be noticed very plainly during the pairing season. A female of the Vapourer Moth (Orayia) will be enclosed in a wooden pill box. She till then attract males from all direc of a mile or two. 